\title{
Strategies to increase zinc deficiency tolerance and homeostasis in plants
}

\section{Ariadne Ribeiro Henriques ${ }^{1}$, Antonio Chalfun-Junior ${ }^{*}$, Mark Aarts ${ }^{2}$}

\author{
'Laboratório de Fisiologia Molecular de Plantas, Departamento de Biologia, Universidade Federal de Lavras, \\ Lavras, MG, Brasil. \\ ${ }^{2}$ Laboratory of Genetics, Wageningen University, The Netherlands. \\ *Corresponding author: chalfunjunior@dbi.ufla.br
}

Received: 13 December 2011; Accepted: 19 June 2012

\begin{abstract}
Zinc deficiency is a global problem of considerable importance for agriculture and human health. Under zinc deficiency conditions, many essential zinc-dependent physiological functions are unable to operate normally, and the cellular homeostasis is adversely affected. This paper described the potential damages that low-zinc bioavailability in soil can have for plants, humans, and animals. In addition, current knowledge on physiological and molecular aspects of zinc homeostasis in plants and strategies used to increase zinc deficiency tolerance were discussed.
\end{abstract}

Keywords: biofortification, mineral nutrition, plant abiotic stress, plant nutrition.

\section{INTRODUCTION}

Plants are autotrophic organisms that have the ability to use solar energy to synthesize vital components from carbon dioxide, water, and nutrients. Minerals, macro and micronutrients are essential to plant growth and development. Their absence prevents plants from completing their life cycle (Ramesh et al., 2004), due to their essential role in physiological and metabolic processes in the plant. Zinc is a vital micronutrient for all organisms. This element is involved in many reactions of the cellular metabolism, including biological processes, such as antioxidative defense, protein synthesis, carbohydrate metabolism, auxin metabolism, and stability of genetic materials (Clemens, 2006; Broadley et al., 2007). Thus, zinc deficiency stress in plants, normally due to low-zinc bioavailability in soil, causes significant decreases in the productivity and nutritional quality of food.

When facing zinc shortage, plants undergo a range of physiological and molecular adjustment in order to maintain cellular homeostasis and to avoid abrupt changes in the dynamic and complex process of development (Grusak, 2002). As the natural response mechanism to overcome a low zinc level in the cell, plants increase the expression of several genes encoding zinc transporters and metal chelator biosynthesis enzymes involved in zinc uptake from the soil (van de Mortel et al., 2006). Since there appears to be genetic variation for this ability, plant breeding and genetic engineering approaches can be used to develop new high-zinc content crop genotypes. They are expected to increase the crop production in areas with low-zinc bioavailability and alleviate human malnutrition problems due to zinc deficiency (Cakmak et al., 2010; Gómez-Galera et al., 2010).

This manuscript aimed at providing an overview about zinc deficiency problems in the world, with emphasis on soil-plant-human health interactions. We also described the current strategies that have been used to mitigate such problem. 


\section{ZINC DEFICIENCY, A GLOBAL PROBLEM}

Zinc deficiency in soils is a serious global problem that affects many agricultural soils. It is estimated that about half of the cultivated soils in the world contains reduced amounts of bioavailable zinc (Figure 1). This problem is aggravated mainly in arid and semi-arid regions, due to low organic matter and soil moisture as well as high levels of $\mathrm{pH}$ and $\mathrm{CaCO}_{3}$ (Cakmak, 2008; Gonçalves Junior, 2010). The low availability of this metal in the soil limits zinc uptake by plants, resulting in significant decreases in both productivity and nutritional quality of food.

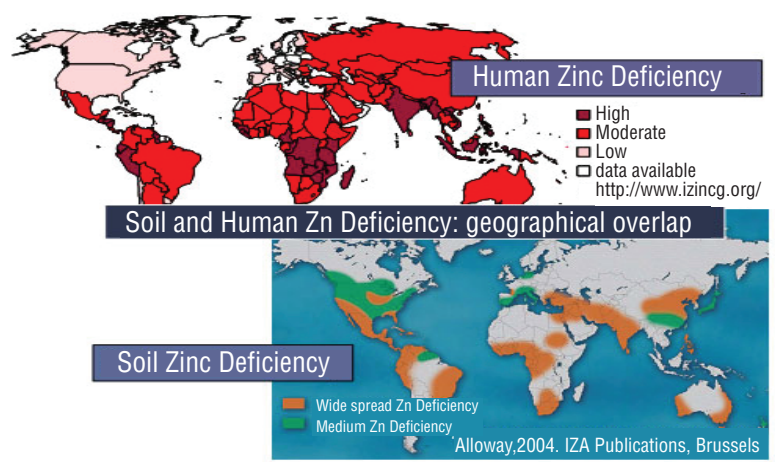

Source: Doctor Ismail Cakmak.

Figure 1. Overlap between geographical regions with soil zinc deficiency (Cakmak, 2011).

Reduction in both growth and in yield happens at low-zinc concentrations in the shoot (Cakmak, 2011). In it, there is a range from 30 and $100 \mu \mathrm{g}$ zinc $\mathrm{g}^{-1}$ dry weight (DW) to be sufficient to support adequate plant growth, reaching a critical point when the $\mathrm{Zn}$ concentration is below $100 \mu \mathrm{g} \mathrm{g}{ }^{-1}$ of dry weight in shoot meristems of rice, due to the disintegration of the 80S ribosomes. In addition to that, the same concentration, or most likely even a higher one, is required to maintain protein synthesis in other meristematic tissues. This required amount is five to ten-fold higher when compared to mature leaves, which shows the importance of the nutrient to keep right growth (Marschner, 1995), and even for optimal growth, plants need to keep a tight control over zinc homeostasis.

Zinc is vital for the functionality of more than 300 enzymes. It can act as a functional, structural, or regulatory cofactor of a large number of enzymes. Some enzymes, such as alcohol dehydrogenase, Cu-Zn superoxide dismutase, and carbonic anhydrase, have zinc in their structure. Other enzymes, such as aldolases, enolase, isomerases, peptidases, transfosforylases and RNA and DNA polymerases, require zinc for enzymatic activity
(Guerinot and Eide, 1999; Buchanan et al., 2000). The structural and functional integrity of cell membranes is also influenced by zinc, which acts in stabilization of biomembranes by interaction with phospholipids and sulphydril groups of membrane proteins. Zinc deficiency in plants causes biochemical changes in membranes, which modify the permeability and architecture of biological membranes. The protection against the peroxidation of membrane lipids and proteins has been shown to be the major role of zinc in membranes (Marschner, 1995; Cakmak, 2011).

Delayed and reduced growth, small and malformed leaves, short internodes and yellowing effects are common symptoms of plants growing on low-zinc supply, all largely attributed to the disturbance of auxin metabolism. However, the way in which zinc deficiency affects indole3 -acetic acid (IAA) metabolism has not been clear yet. It is believed that zinc is involved in both IAA biosynthesis and in protecting IAA from oxidative degradation by reactive oxygen species - ROS (Robson, 1994; Cakmak, 2011).

As a result of its vital importance to plants, zinc deficiency affects the plant as a whole, causing serious problems in the metabolism of carbohydrates, mainly by the severe decline in photosynthesis and in sugar metabolism, and the synthesis of proteins, attributed to a sharp reduction in transcription, deformation, and reduction of ribosomes (Marenco and Lopes, 2007). The main damage of low-zinc supply on protein metabolism acts through gene expression by affecting RNA and DNA structure and the stability and function of zinc finger proteins, which are required for the expression and regulation of gene expression (Marschner, 1995).

The regions with zinc-deficient soils are strongly correlated with the ones with high incidence of human $\mathrm{Zn}$ deficiency. The cultivation of food crops on Zn-deficient is problematic, leading to low yields, low zinc content in food, and low income to farmers, preventing them to invest in zinc fertilizers. Especially when the crops in question constitute the main food and feed sources for the local population, dietary zinc deficiency will be inevitable in both humans and domestic animals (Erenoglu et al., 2010). Cereals-based foods are the most important source of calories in most developing countries. As an example, wheat cultivation on Zn-deficient soils in Turkey lead to the production of wheat (Triticum aestivum, L.) grains with approximately $50 \%$ reduction in zinc content compared to wheat grown with sufficient zinc supply (Cakmak, 2011).

Zinc deficiency in humans is a nutritional problem worldwide. It is estimated that one-third of the world population (around 2 billion people) suffers from mild zinc deficiency and over 450,000 children die each year due 
such deficiency (Welch and Grahan, 2004; Cakmak et al., 2010). According to the World Health Organization (2003), zinc deficiency in humans can result in several undesirable consequences, including diminished learning ability, impaired immune response, dysfunction of reproductive system, and reduced growth rates on infants. Thus, ensuring adequate dietary intake of zinc is essential to reduce illness and to decrease child mortality in developing countries.

\section{STRATEGIES USED TO INCREASE ZINC DEFICIENCY TOLERANCE}

The impacts caused by zinc deficiency in agriculture and in humanhealth have beenstudiedfordecades. Many physiological mechanisms, such as root uptake and translocation, zinc sequestration in leaves, biochemical utilization of zinc and, more recently, identification and manipulation of candidate genes for proteins zinc transporters and chelator enzymes have been investigated (Hacisalihoglu and Kochian, 2003), and these findings have contributed to unraveling the molecular system of zinc homeostasis in plants.

A fast and easy solution to prevent zinc deficiency plants is Zn supplementation by applying fertilizer (Cakmak, 2008). However, there are costs associated with the application, and even though the benefits are wider, this poses a threshold for application. In addition, zinc fertilizer application effect can be impaired by physical and chemical characteristics of soil, which reduce the availability of $\mathrm{Zn}$ to plants, leading to a disappointing experience for farmers. An promising and cost-effective alternative strategy is improving plant zinc use efficiency and grain zinc content by plant breeding or genetic engineering. Such biofortification approach is one of the aims of the international Harvest Plus Consortium, which supports the development of new high-zinc content genotypes for increased zinc content in food and crops (Cakmak et al., 2010; Gómez-Galera et al., 2010). Although biotechnological techniques advances and significant progress in understanding structures involved in metal homeostasis have driven research in this field, still little is known about the regulators of zinc homeostasis network in plants.

\section{ZINC HOMEOSTASIS}

Zinc is a transition metal essential for terrestrial life, as already described. However, it is only required at low concentrations, making it function as a micronutrient. Concentrations between 30 and $100 \mu \mathrm{g}$ zinc $\mathrm{g}^{-1}$ DW are enough to support adequate plant growth, whereas zinc toxicity symptoms are observed in concentrations above $300 \mu \mathrm{g} \mathrm{g}^{-1}$ DW for species that are not adapted to highzinc exposure (Marschner, 1995; van de Mortel et al., 2006). Therefore, for optimal growth, plants need to keep tight control over zinc homeostasis.

Zinc homeostasis requires a complex network of cellular or tissue specific functions to control metal uptake, accumulation, trafficking, and detoxification. The ability to take up $\mathrm{Zn}$ of higher plants depends much more on its bioavailability from soil than on the absolute soil concentrations. Zinc bioavailability is modulated by various physical and chemical soil factors. Zinc solubility in soil decreases due to high levels of calcium carbonate, metal oxides, and $\mathrm{pH}$ and low levels of organic matter and soil moisture as well as high amounts of phosphate (Robson, 1994; Cakmak, 2011). When available in the soil solution, zinc is absorbed and transported in the divalent ion form $\left(\mathrm{Zn}^{+2}\right)$ from roots to shoots through the xylem, being easily retranslocated by phloem (Clemens, 2001). This transport of ions and molecules from epidermal and cortical cell to xylem can occur through the symplastic or apoplastic route.

Following the apoplastic route, zinc and other minerals (essential and nonessential) traverse with water through cell walls and intercellular spaces outside the cell membrane to the endodermis, where Casparian strips force all solutes that need to be transported through xylem to enter endodermis cells by crossing the plasma membrane. The symplastic route consists of a continuous system of cytoplasmatic transport interconnecting cells by plasmodesmata. Upon entering the stele of the plant root, ions are transported symplastically until they reach the xylem parenchyma cells, which act in loading minerals into the xylem (Taiz and Zeiger, 2004; Broadley et al., 2007).

Regardless of the chosen path, the solutes that reach the xylem parenchyma cells are transferred to the xylem elements in a tightly-controlled process mediating membrane transport. Via the xylem sap, the minerals are released in the apoplast of the leaves and are subsequently distributed intracellularly (Clemens et al., 2002).

Zinc distribution, transport, and accumulation are affected by the level of zinc supply to the plant, as well as by mycorrhiza fungi, reducing the distance across which nutrients have to be transported in the soil (Marschner, 1995). At low or adequate zinc supply, roots, vegetative shoots, and reproductive tissues have higher zinc concentrations in young growing tissues than in mature ones. When exposed to toxic zinc levels, tolerant plants can accumulate zinc in the root cortex cells and in leaves, specifically in the cell wall or vacuoles (Robson, 1994). 


\section{GENES INVOLVED IN ZINC HOMEOSTASIS IN PLANTS}

Accumulation of zinc or other metallic minerals depends on the uptake capacity and on intracellular binding sites. The metal accumulation rates are affected by the concentration and affinities of chelating molecules and by the presence and selectivity of transport activities (Clemens et al., 2002). Metal transporters are required for metal uptake and efflux or intracellular metal transport in the plant, and metal chelators contribute to metal detoxification by buffering free cytosolic metal concentrations. Therefore, both play a major role in metal homeostasis. Several studies have focused on the identification and manipulation of genes for zinc transporter proteins and chelator biosynthesizing enzymes.

The natural resistance associated macrophage protein (NRAMP) is a family of proteins whose function is to take up and transport metal. Research in Arabidopsis thaliana (L.) Heynh (Arabidopsis) showed that NRAMP transporters have limited metal specificity. AtNRAMP3 and AtNRAMP4 are localized to the vacuolar membrane and are involved in the intracellular iron transport (Thomine et al., 2000). These genes show similar expression levels in most tissues (Grotz and Guerinot, 2006), and only double mutants show a mutant phenotype, i.e., they are functionally redundantly (Palmer and Guerinot, 2003). Thomine et al. (2003) reported that AtNRAMP3 controls the accumulation of zinc and manganese in roots upon iron starvation.

Another family of transporters involved in zinc efflux is the $P_{1 B}$-ATPase. Arabidopsis has eight genes encoding $P_{1 B}$ ATPases that differ in their structure, function, and regulation (Eren and Argüello, 2004). Among these, HMA1, HMA2, HMA3, and HMA4 are involved in zinc transport (Hussain et al., 2004). AtHMA1 localizes in the chloroplast envelop and can contribute to $\mathrm{Zn}$ detoxification under excess zinc conditions (Kim et al, 2009). The AtHMA2 gene encodes a $\mathrm{Zn}^{+2}$-ATPase located in the plasma membrane. Expression is induced by cadmium and zinc (Eren and Argüello, 2004). The AtHMA3 protein possibly mediates zinc hyperaccumulation, since zinc hyperaccumulator species show higher expression of HMA3 than the non-hyperaccumulator ones, such as Arabidopsis (Becher et al., 2004; van de Mortel et al., 2006; Hassan and Aarts, 2011).

Recently, HMA3 has been cloned from Thlaspi carulescens Alpine Penny-cress (Ueno et al., 2011), and rice (Ueno et al., 2010), therefore it is a vacuolar influx transporter, important for cadmium tolerance in both species. This suggests that different homologs of HMA3 may have different metal-substrate specificity. AtHMA4, similar to AtHMA2 and acting alike, plays an important role in translocation of zinc, specifically in loading of zinc into the xylem (van de Mortel et al., 2006; Waters and Sankaran, 2011). Hussain et al. (2004) reported that both HMA2 and HMA4 are essential to zinc homeostasis and they show a functional redundancy.

Members of the cation diffusion facilitator (CDF) family play an important role in living organisms, as they control cation concentrations in cells through sequestration into internal compartments and efflux from cell (Gustin et al., 2011). MTP1 and MTP3 seem to be involved in the sequestration of zinc in root vacuoles and can act to limit its translocation to the shoot (Arrivault et al., 2006). In addition, when MTP1 is overexpressed in Arabidopsis, an increased resistance to zinc and higher zinc content in roots are observed (Kobae et al., 2004). MTP2 is also involved in zinc homeostasis. Under zinc deficiency, MTP2 expression increases suggesting it to play a specific function in counteracting the effect of zinc deficiency (van de Mortel et al., 2006). MTP8 is another member of the CDF family, which in addition to mediating manganese transport may also function in zinc uptake (van de Mortel et al., 2006).

The zinc regulated transporter (ZRT), iron-regulated transporter (IRT)-like protein (ZIP) family contains many members thought to be involved in transporting zinc into the cytosol across the plasma membrane, which is an important process for plant zinc uptake (Palmer and Guerinot, 2009; Song et al., 2010). ZIP transporters have eight transmembrane domains and a histidine-rich variable loop between transmembrane domains III and IV that appears to be conserved among all family members (Colangelo and Guerinot, 2004). In Arabidopsis, there are 15 ZIP gene members, ZIP1-12 and IRT1-3, of which at least ten members (ZIP1, 2, 3, 4, 5, 9, 10,11, 12 and IRT3) appear to play a role in plant zinc uptake. Approximately half of the ZIP genes (ZIP1, 3, 4, 5, 9, 10, and IRT3) is induced in response to zinc deficiency (Wintz et al., 2003; van de Mortel et al., 2006; Assunção et al., 2010).

Metal chelators are also important for metal homeostasis. Nicotianamine (NA) is a metal-chelating compound, made by the action of NA synthase that binds zinc, as well as iron, copper, and nickel (Curie et al., 2009). NA is thought to be involved in long-distance transport, perhaps also playing a role in the entry of metals into the phloem or xylem through metal-NA chelate transporters of the Yellow Stripe-like (YSL) family (Gendre et al., 2007). NA synthase is encoded by four genes in Arabidopsis, AtNAS1-AtNAS4, which act functionally redundant, although they show different expression patterns, suggesting that each NAS gene may have a specialized function (Klatte et al., 2009). As an example, only AtNAS2 and AtNAS4 are highly expressed in roots under zinc deficiency (van de Mortel et al., 2006). 


\section{ZINC HOMEOSTASIS REGULATION}

The growth and development of all organisms depend on adequate gene expression regulation. Transcription factors play an essential role in modulating gene expression by controlling transcription initiation rates. Thus, strategies that seek to modify the transcription expressions factors have shown a more efficient and promising approach than the modification of a single structural gene in Genetic Engineering (Yang et al., 2009). Currently, there are few groups focusing on this approach, however they obtained very promising results with regards to engineering environmental stress tolerance. In Arabidopsis, overexpression of the transcription factor DREB1A, driven either by a constitutive (CaMV 35S) or conditional promoter (rd29A), increases tolerance to drought, cold, and salt stress (Kasuga et al., 2004). Overexpression of an ERF transcription factor TSRF1 enhances the osmotic and drought tolerances (Quan et al., 2010).

Regarding micronutrient response, experiments carried out on rice showed that OsIR02 overexpression, a transcription factor involved in the regulation of iron homeostasis genes in rice (Oriza sativa L.), increases iron deficiency tolerance by improving growth and yield of rice plants (Ogo et al., 2011). Recently, two transcription factors, bZIP23 and bZIP19, which are involved in the regulation of zinc deficiency response in Arabidopsis, were identified. These transcription factors recognize 8 to 10 bp palindromic motifs called zinc deficiency response elements, found in tandem in promoters of several zinc homeostasis genes, activation of which constitutes the primary response to zinc deficiency (Assunção et al., 2010). Modification of these transcription factors to control zinc deficiency tolerance and accumulation is in progress (Henriques and Aarts, unpublished results). The simultaneous expression of a set of genes implicated in the same process is a promising strategy to enhance productivity and stress tolerance in plants, when activation of multiple genes at the same time is necessary to obtain an effective stress response. Still, although the listed findings offer interesting options to try and modify plant micronutrient deficiency response, the control of post-transcriptional and -translational regulation also deserves attention.

\section{CONCLUSIONS}

In terms of understanding the roles of genes involved in uptake and translocation of zinc in plants, a lot has been achieved, but information on where in the plant each transporter functions and how each one is controlled in response to nutrient availability remains still unclear. The identification of transcription factors involved in the control of zinc deficiency response offers interesting opportunities to modulate zinc deficiency responsive gene expression to make plants less sensitive to zinc deficiency or to confer a constitutive zinc deficiency response, which can induce plants to over-accumulate metals. Therefore, understanding the regulator identity of the zinc homeostasis network in plants should provide new insights for the development of crops in areas suffering from low zinc bioavailability and for biofortification strategies. Furthermore, understanding how zinc interacts to other metals, such as cadmium and lead, during its absorption is important to be known, avoiding undesirable accumulation of such heavy metals in plants.

ACKNOWLEDGEMENTS: We would like to thank the Coordenação de Aperfeiçoamento de Pessoal de Nível Superior (CAPES) for their financial support to Ariadne Ribeiro Henriques.

\section{REFERENCES}

Arrivault S, Senger T, Kramer U (2006) The Arabidopsis metal tolerance protein AtMTP3 maintains metal homeostasis by mediating $\mathrm{Zn}$ exclusion from the shoot under Fe deficiency and Zn oversupply. Plant J. 46:861-879.

Assunção AGL, Herrero E, Lin YF, Huettel B, Talukdar S, Smaczniak C, et al. (2010) Arabidopsis thaliana transcription factors bZIP19 and bZIP23 regulate the adaptation to zinc deficiency. Proc. Natl. Acad. Sci. USA. 107:10296-10301.

Becher M, Talke IN, Krall L, Krämer U (2006) Cross-species microarray transcript profiling reveals high constitutive expression of metal homeostasis genes in shoots of the zinc hyperaccumulator Arabidopsis halleri. Plant J. 37:251-268.

Broadley M, White PJ, Hammond JP, Zelko I, Lux A (2007) Zinc in plants. New Phytol. 173:677-702.

Buchanan B, Gruissem W, Jones R (2000) Biochemistry and molecular biology of plants. 1th ed. American Society of Plant Physiologists, Rockville.

Cakmak I (2008) Enrichment of cereal grains with zinc: agronomic or genetic biofortification? Plant Soil 302:1-17.

Cakmak I (2011) Zinc plays critical role in plant growth. Available: http:// www.zinc.org/crops/resourceserve/zinc_plays_critical_role_in_plant growth. Accessed: 17 Apr 2011.

Cakmak I, Pfeiffer W, Mcclafferty B (2010) Biofortification of durum wheat with zinc and iron. Cereal Chem. 87:10-20.

Clemens S (2001) Molecular mechanisms of plant metal tolerance and homeostasis. Planta 212:475-486.

Clemens S (2006) Toxic metal accumulation, responses to exposure and mechanisms of tolerance in plants. Biochimie 88:1707-1719.

Clemens S, Palmgren M, Kramer U (2002) A long way ahead: understanding and engineering plant metal accumulation. Trends Plant Sci. 7:309-315.

Colangelo E, Guerinot M (2004) Put the metal to the petal: metal uptake and transport throughout plants. Curr. Opin. Plant Biol. 9:322-330.

Curie C, Cassin G, Couch D, Divol F, Higuchi K, Le Jean M, et al. (2009) Metal movement within the plant: contribution of nicotianamine and yellow stripe 1-like transporters. Ann. Bot. 103:1-11. 
Eren E, Argüello J (2004) Arabidopsis HMA2, a divalent heavy metaltransporting $\mathrm{P}_{\mathrm{IB}}$-Type ATPase, is involved in cytoplasmic $\mathrm{Zn}^{2+}$ homeostasis. Plant Physiol. 136:3712-3723.

Erenoglu E, Kutman UB, Ceylan Y, Yildiz B, Cakmak I (2010) Improved nitrogen nutrition enhances root uptake, root-to-shoot translocation and remobilization of zinc $\left({ }^{65} \mathrm{Zn}\right)$ in wheat. New Phytol. 189:438-448.

Gendre D, Czernic P, Conéjéro G, Pianelli K, Briat JF, Lebrun M, et al. (2007) TcYSL3, a member of the YSL gene family from the hyperaccumulator Thlaspi caerulescens, encodes a nicotianamine-Ni/Fe transporter. Plant J. 49:1-15.

Gómez-Galera S, Rojas E, Sudhakar D, Zhu C, Pelacho AM, Capell T, et al. (2010) Critical evaluation of strategies for mineral fortification of staple food crops. Transgenic Res. 19:165-180.

Gonçalves Junior AC, Nacke H, Marengoni NG, Carvalho EA, Coelho GF (2010) Produtividade e componentes de produção da soja adubada com diferentes doses de fósforo, potássio e zinco. Cienc. Agrotec. 34:660-666.

Grusak M (2002) Enhancing mineral content in plant food product. J. Am. Coll. Nutr. 21:178-183.

Grotz N, Guerinot M (2006) Molecular aspects of Cu, Fe and Zn homeostasis in plants. Biochim. Biophys. Acta 1763:595-608.

Guerinot M, Eide D (1999) Zeroing in on zinc uptake in yeast and plants. Curr. Opin. Plant Biol. 2:244-249.

Gustin JL, Zanis MJ, Salt DE (2011) Structure and evolution of the plant cation diffusion facilitator family of ion transporters. BMC Evol. Biol. 11:76.

Hacisalihoglu G, Kochian L (2003) How do some plants tolerate low levels of soil zinc? Mechanims of zinc efficiency in crop plants. New Phytol. 159:341-350.

Hassan Z, Aarts M (2011) Opportunities and feasibilities for biotechnological improvement of $\mathrm{Zn}, \mathrm{Cd}$ or Ni tolerance and accumulation in plants. Environ. Exp. Bot. 72:53-63.

Hussain D, Haydon MJ, Wang Y, Wong E, Sherson SM, Young J, et al. (2004) P-type ATPase heavy metal transporters with roles in essential zinc homeostasis in Arabidopsis. Plant Cell 16:1327-1339.

Kasuga M, Miura S, Yamaguchi-Shinozaki K (2004) A combination of the Arabidopsis DREB1A gene and stress inducible rd29A promoter improved drought and low temperature stress tolerance in tobacco by gene transfer. Plant Cell Physiol. 45:346-350.

Klatte M, Schuler M, Wirtz M, Fink-Straube C, Hell R, Bauer P (2009) The analysis of Arabidopsis nicotianamine synthase mutants reveals functions for nicotianamine in seed iron loading and iron deficiency responses. Plant Physiol. 150:257-271.

Kim YY, Choi H, Segami S, Cho HT, Martinoia E, Maeshima M, et al. (2009) AtHMA1 contributes to detoxification cation of excess $\mathrm{Zn}(\mathrm{II})$ in Arabidopsis. Plant J. 58:737-753.

Kobae Y, Uemura T, Sato MH, Ohnishi M, Mimura T, Nakagawa T, et al. (2004) Zinc transporter of Arabidopsis thaliana AtMTP1 is localized to vacuolar membranes and implicated in zinc homeostasis. Plant Cell Physiol. 45:1749-1758.

Marenco R, Lopes N (2007) Fisiologia vegetal. 2. ed. MG: UFV, Viçosa.

Marschner H (1995) Mineral nutrition of higher plants. 2th ed. Academic, London.
Ogo Y, Itai RN, Kobayashi T, Aung MS, Nakanishi H, Nishizawa NK, et al. (2011) OsIR02 is responsible for iron utilization in rice and improves growth and yield in calcareous soil. Plant Mol. Biol. 75:593-605.

Palmer C, Guerinot M (2009) Facing the challenges of Cu, Fe and Zn homeostasis in plants. Nature Chem. Biol. 5:333-340.

Quan R, Hu S, Zhang Z, Zhang H, Zhang Z, Huang R Quan R, et al. (2010) Overexpression of an ERF transcription factor TSRF1 improves rice drought tolerance. Plant Biotech. J. 8:476-88.

Ramesh S, Choimes S, Schachtman D (2004) Over-expression of an Arabidopsis transporter in Hordeum vulgare increases short-term zinc uptake after zinc deprivation and seed zinc content. Plant Mol. Biol. 5:373-385.

Robson AD (1994) Zinc in soils and plants. Springer, New York.

Song WY, Choi KS, Kim do Y, Geisler M, Park J, Vincenzetti V, Schellenberg $\mathrm{M}$, et al. Arabidopsis PCR2 is a zinc exporter involved in both zinc extrusion and long-distance zinc transport. Plant Cell 22:2237-2252.

Taiz L, Zeiger E (2004) Fisiologia vegetal. 3. ed. Artmed, Porto Alegre.

Thomine S, Wang R, Ward JM, Crawford NM, Schroeder JI Thomine S, et al. (2000) Cadmium and iron transport by members of a plant metal transporter family in Arabidopsis with homology to Nramp genes. Proc. Natl. Acad. Sci. USA. 97:4991-4996.

Thomine S, Lelièvre F, Debarbieux E, Schroeder JI, Barbier-Brygoo H Thomine S, et al. (2003) AtNRAMP3, a multispecific vacuolar metal transporter involved in plant responses to iron deficiency. Plant $\mathrm{J}$. 34:685-695.

Ueno D, Yamaji N, Kono I, Huang CF, Ando T, Yano M, et al. (2010) Gene limiting cadmium accumulation in rice. Proc. Natl. Acad. Sci. USA. 107:16500-16505.

Ueno D, Milner MJ, Yamaji N, Yokosho K, Koyama E, Clemencia Zambrano M, Kaskie M, et al. (2011) Elevated expression of TcHMA3 plays a key role in the extreme $\mathrm{Cd}$ tolerance in a $\mathrm{Cd}$-hyperaccumulating ecotype of Thlaspi caerulescens. Plant J. 66:852-862.

van de Mortel JE, Almar Villanueva L, Schat H, Kwekkeboom J, Coughlan S, Moerland PD, et al. (2006) Large expression differences in genes for iron and zinc homeostasis, stress response, and lignin biosynthesis distinguish roots of Arabidopsis thaliana and the related metal hyperaccumulator Thlaspi caerulescens. Plant Physiol. 42:1127-1147.

Waters B, Sankaran R (2011) Moving micronutrients from the soil to the seeds: genes and physiological processes from a biofortification perspective. Plant Sci. 180:562-74.

Wintz H, Fox T, Wu YY, Feng V, Chen W, Chang HS, et al. (2003) Expression profiles of Arabidopsis thaliana in mineral deficiencies reveal novel transporters involved in metal homeostasis. J. Biol. Chem. 278:4764447653.

Welch R, Graham R (2004) Breeding for micronutrients in staple food crops from a human nutrition perspective. J. Exp. Bot. 55:353-364.

World Health Organization (2003) World health report 2003: comparative quantification of health risks. Washington. Available: http://www. who.int/publications/cra/chapters/volume1/0257-0280.pdf. Accessed: 30 May 2011.

Yang 0, Popova OV, Süthoff U, Lüking I, Dietz KJ, Golldack D, et al.(2009) The Arabidopsis basic leucine zipper transcription factor AtbZIP24 regulates complex transcriptional networks involved in abiotic stress resistance. Gene 436:45-55. 